\title{
Numerical simulation of heat transfer over a flat plate with a triangular vortex generator
}

\author{
Morteza Bayareh $^{1}$, Amireh Nourbakhsh ${ }^{2 *}$, Mohammad Erfan Khadivar ${ }^{2}$ \\ ${ }^{1}$ Department of Mechanical Engineering, Shahrekord University, Shahrekord, Iran \\ ${ }^{2}$ Department of Engineering, Bu-Ali Sina University, Hamedan, Iran
}

Corresponding Author Email: nourbakhsh@basu.ac.i

https://doi.org/10.18280/ijht.360443

Received: 17 March 2018

Accepted: 9 October 2018

\section{Keywords:}

vortex generator, Nusselt number, triangular wings, spin angle, longitudinal vortex

\begin{abstract}
In the present work, the effect of the angle of a triangular vortex generator on the heat transfer of a flat plate is investigated. Incompressible three-dimensional fluid flows in a channel with constant temperature boundary condition. The results showed that the Nusselt number increases and the pressure decreases with the Reynolds number. It is demonstrated that the increase in the angle from $30^{\circ}$ to $90^{\circ}$ has a significant effect on the Nusselt number. The pressure drop remains constant at a $60^{\circ}$ angle with increasing Reynolds number. The results revealed that the longitudinal vortices that have an important effect on the heat transfer become stronger at larger angles of the vortex generator.
\end{abstract}

\section{INTRODUCTION}

Heat transfer considerations are the main goal in various industries related to energy conversion such as petrochemicals, oil and gas, nuclear, air conditioning, etc. The main goal is to enhance heat transfer rate which can be done in a variety of ways, including increasing the heat exchange rate or increasing mixing. One of these methods is to employ the vortex generators. The vortex generators change the distribution of fluid velocity and flow pattern along the wall. They provide a laminar fluid mixing close to the wall and high velocity outside the boundary layer, which has a significant effect on the improvement of heat transfer.

The vortex generator and its effects on the behavior of the boundary layer have probably been studied for the first time by Schubauer and Spangenberg [1]. They found that the longitudinal vortex leads to separation delay in the boundary layer. This phenomenon can be suited for conditions like cross-sectional aerodynamics. The effect of the vortex generator on the heat transfer rate was first carried out by Johnson and Joubert [2]. Their research on a delta-shaped vortex generator on a cylindrical surface was carried out. The results showed that the local Nusselt number for the vortex generator increases by about $200 \%$ while the total Nusselt number remains constant. Dupont et al. [3] experimentally studied an isothermal flow in a compressed heat exchanger with a vortex generator and concluded that smooth-shaped vortex generators results in an increase in heat transfer. Fiebig et al. [4] conducted a numerical and experimental study on a delta-shaped wing along with a rectangular wing in a laminar for for different attack angles and various Reynolds numbers. They found that local heat transfer for the delta-shaped wings is higher than that for a rectangular one. Russell et al. [5] studied experimentally the effect of a pair of vortex generators in a channel and evaluated the characteristics of heat transfer and pressure drop. Influence of geometric parameters on heat transfer enhancement has been studied by many researchers [6-8]. Also, the effect of vortex generator height $[9,10]$, their arrangement [11-12], and the ratio of the vortex generator size to the channel height [13] have been considered. Wang et al. [13] experimentally studied the increase of heat transfer in a low width rectangular channel with longitudinal vortex generators. They found that heat transfer increases by 10 to 45 percent. Wu et al. [14] examined the effect of vortex generator position in a channel on improving the heat transfer and pressure drop in a rectangular channel and concluded that increasing the surface of the vortex generator leads to an increase in heat transfer and Pressure drop. Wu and Tao [15] found that heat transfer of a laminar flow in a channel with a rectangular wing increases with the Reynolds number and angle of attack. They also demonstrated that he pressure drop increases rapidly with increasing attack angle. Tiggelbeck et al. [16] investigated the improvement of heat transfer and pressure drop for various vortex generators in turbulent flow and found that a vortex rectangular in a rectangular channel leads to better performance than other geometries. Jentry and Jacobi [17] experimentally investigated the heat transfer of a channel with delta-shaped wings and found that the increase of local heat transfer coefficient in the secondary flow region is up to $300 \%$, the enhancement of average heat transfer coefficient in the channel is up to $55 \%$ and the increase in the pressure drop is up to $100 \%$. Yang et al. [18] studied the effect of different attack angles of the delta-shaped vortex generators on the increase in heat transfer. Their research showed that the highest increase in heat transfer occurs at an angle of $45^{\circ}$. Liou et al. [19] experimentally studied the use of crystalline thermosetting of heat transfer and fluid flow in a squareshaped channel with 12 different types of vortex generators. Zhu et al. [20] numerically evaluated turbulence flow and heat transfer in a channel with longitudinal vortex generators using the $\mathrm{k}-\varepsilon$ turbulence model. Fiebig [21] experimentally investigated the flow and heat transfer characteristics in a rectangular channel with four longitudinal vortex generators. $\mathrm{He}$ found that longitudinal vortices reduce the critical Reynolds number. He also showed that under constant heat flux, rectangular-shaped wings produce a lower pressure drop than rectangular ones. Hiravennavar et al. [22] performed numerical simulations for a laminar flow passes over delta- 
shaped wings at different Reynolds numbers. Their results showed that the difference between the increase in heat transfer between a narrow-thickness vortex generator and a vortex generator with zero thickness (ideal vortex generator) is negligible. Ferrouillat et al. [23] studied the turbulent flow passes over a delta-shaped vortex generator. They found that the delta-shaped one has a better performance than a rectangular one. They revealed that the heat transfer and, consequently, the mixing efficiency is optimal when the distance between the rows of generators is seven to ten times of the height of the entire channel. Abdollahi and Shams [24] performed a numerical study for the shape and the angle of attack of the vortex generators and provided the effect of vortices on the overall performance of the heated wells. The results showed that at low Reynolds numbers, the angular momentum of the attack has no significant effect on the heat transfer coefficient, but at high Reynolds numbers, it has an important effect on heat transfer.

There are two ways to increase convective heat transfer: an increase in the heat transfer area and an increase in the convective heat transfer coefficient. In order to promote thermal performance, there are several methods that are classified into three broad categories: active methods, passive methods, and hybrid methods (combining active and passive methods). In active methods, high-power equipment are needed in order to achieve high heat transfer rates. However, they are not used due to high costs. The passive methods usually utilize geometrical and surface-related modifications by additional devices and connections, and by changing the flow behavior. They increase the heat transfer and also the pressure drop. The use of vortex generators is one of the most innovative passive methods. These devices make the vortexes of different sizes formed on the back of that device, which makes the flow of fluid flow and heat transfer better. There are three different methods. Based on their applications, these methods are divided into different groups: active vortex generators, generating vortex generators and hybrid vortex generators. There are three distinct mechanisms to intensify convection heat transfer: Reducing the thickness of the boundary layer, vortex generation, and flow destabilization. All of these three mechanisms may be generated by vortex generators.

In the present study, forced heat transfer from a flat plate with a delta-shaped vortex generator with a constant attack angle relative to the flow and variable angles relative to the flat plate is investigated. The delta-shaped vortex generator are usually used in practical situations. Also, changing the angle to the surface creates different size of the vortices behind the walls results in better mixing of fluid flow and heat transfer. The main objective of this research is to investigate the angle effect on the heat transfer and vortex pattern. The variables studied are the angle, Reynolds number and Nusselt number.

\section{GOVERNING EQUATIONS}

The governing equations for the present problem are continuity, momentum and energy equations. The fluid is assumed to be Newtonian and incompressible. Also, its properties do not change with the temperature. The flow regime is laminar and the volumetric forces are neglected. The governing equations are as follows:

$$
\nabla \cdot \vec{u}=0
$$

$$
\begin{aligned}
& \rho(\vec{u} . \nabla) \vec{u}=-\nabla p+\mu \nabla^{2} \vec{u} \\
& \rho C_{P} \nabla \cdot(\vec{u} T)=k_{f} \nabla \cdot(\nabla T)
\end{aligned}
$$

where, $u$ indicates the velocity vector, $C_{P}$ is the specific heat at constant pressure, $p$ the pressure, $\mu$ the fluid dynamic viscosity, $T$ the temperature, $\rho$ the fluid density, and $k_{f}$ the thermal conductivity of the fluid.

In the present work, the input boundary condition is defined as the inlet velocity and the boundary condition of the output as outflow. Since the geometry is symmetrical, one half of the channel is considered to reduce the computational costs. Therefore, the boundary condition of symmetry is used, as shown in Figure 1. No-slip boundary condition is imposed on the walls. The channel includes two delta-shaped vortex generators that are located on its lower surface. The calculations are done for two Prandtl numbers of 0.707 and 5.83. The input fluid temperature is assumed to be equal to 293 $\mathrm{K}$ and the temperature of the channel walls, as well as the wing surface is $333 \mathrm{~K}$. The SIMPLE algorithm is used to solve the governing equations. It should be noted that the results are numerically accurate to $10^{-5}$.

Also, the properties of air are: $\rho=1.1614 \mathrm{~kg} / \mathrm{m}^{3}, \mu=$ $1.846 \times 10^{-5} \mathrm{~kg} / \mathrm{m} . \mathrm{s}, \mathrm{k}=2.63 \times 10^{-2} \mathrm{~W} / \mathrm{m} . \mathrm{k}$, and $c_{P}=$ $1007 \mathrm{~J} / \mathrm{kg} . \mathrm{k}$.

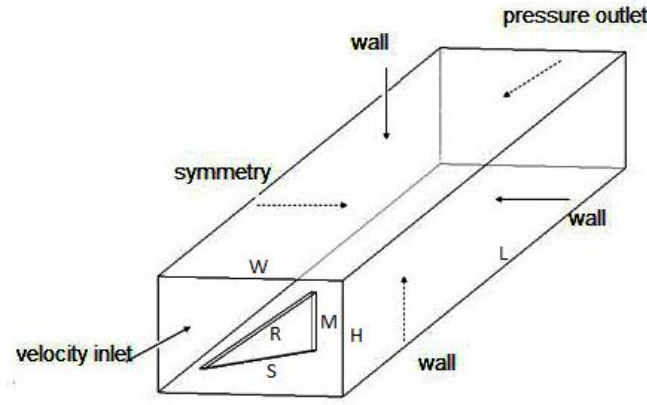

Figure 1. Schematic of the computational domain along with the boundary conditions

Table 1. The dimensions of the channel

\begin{tabular}{|c|c|}
\hline$H$ & $33.6 \mathrm{~mm}$ \\
\hline$W=1.6 \mathrm{H}$ & $61.76 \mathrm{~mm}$ \\
\hline$L=13 \mathrm{H}$ & $561.8 \mathrm{~mm}$ \\
\hline$\alpha$ & $30^{0}$ \\
\hline$\beta$ & $30^{0}, 60^{0}, 90^{0}$ \\
\hline$S=1.5 \mathrm{H}$ & $57.9 \mathrm{~mm}$ \\
\hline$M=0.5 \mathrm{H}$ & $19.3 \mathrm{~mm}$ \\
\hline$R=1.55 \mathrm{H}$ & $59.83 \mathrm{~mm}$ \\
\hline$E=0.052 \mathrm{H}$ & $2 \mathrm{~mm}$ \\
\hline$N=0.1 \mathrm{H}$ & $3.86 \mathrm{~mm}$ \\
\hline
\end{tabular}

In this study, the farthest distance to the end of the computational domain is considered so that the vortices created behind the wing have the proper dimensions for generation and shedding in the flow field and do not affect the 
upstream flow field. In Table 1, the dimensions of the channel are specified.

Figure 2 shows the grid used in the calculations. The Figure indicates that the grid is denser in the vicinity of the vortex generator to capture the density boundary layer.

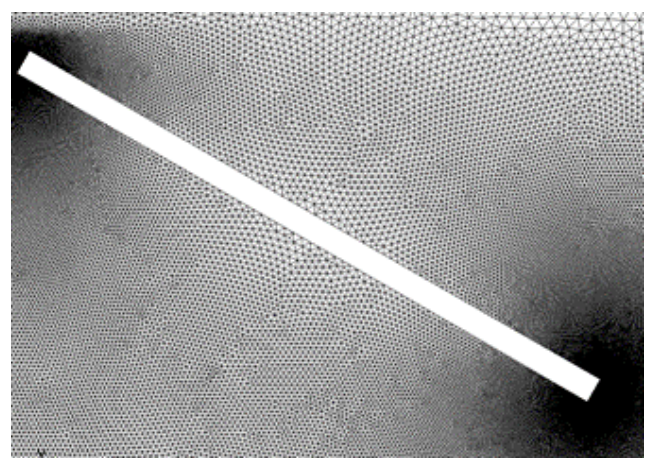

(a)



(b)

Figure 2. The grid used in the present simulations: (a) the bottom surface of the wing, (b) the vortex generator

The Nusselt number is defined as follows:

$N u=h D_{h} / k_{f}$

where $D_{h}=2 \mathrm{H}$ is hydraulic diameter.

Convective heat transfer is calculated by:

$q=h A \Delta T_{l m}$

where,

$A=(2 L W)+(L H)+A_{\text {winglet }}$

$A_{\text {winglet }}=S M$

$\Delta T_{l m}=\frac{\left(T_{\text {in }}-T_{w}\right)-\left(T_{\text {out }}-T_{w}\right)}{\ln \left(\frac{T_{\text {out }}-T_{w}}{T_{\text {in }}-T_{\text {out }}}\right)}$

Also, the pressure drop is calculated by:

$p_{\text {loss }}=\left|\frac{p_{\text {in }}-p_{\text {out }}}{p_{\text {in }}}\right|$

To control the mesh independency of the solution, six different grids at $\mathrm{Re}=911$ and the angle of $90^{\circ}$ are used. Figure 3 shows Nusselt number for different grid resolutions. It can be seen that by increasing the number of nodes, the Nusselt number gradually moves toward a constant number. The resolution of 2000000 is used for further simulations.

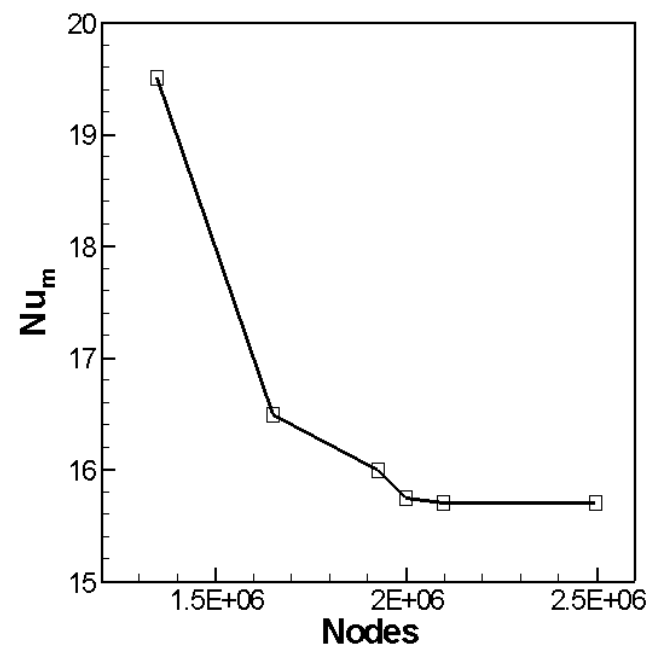

Figure 3. Nusselt number for different grid resolutions

In order to validate the present simulation, the experimental study of Fiebig et al. [4] considering the effect of a triangular vortex generator located on a flat plate fins is simulated. Figure4 shows convective heat transfer coefficient on the fin centerline for the angle of attack of $40^{\circ}$ and $\mathrm{Re}=1815$. The results depicts very good agreement between the present simulation and experimental ones.

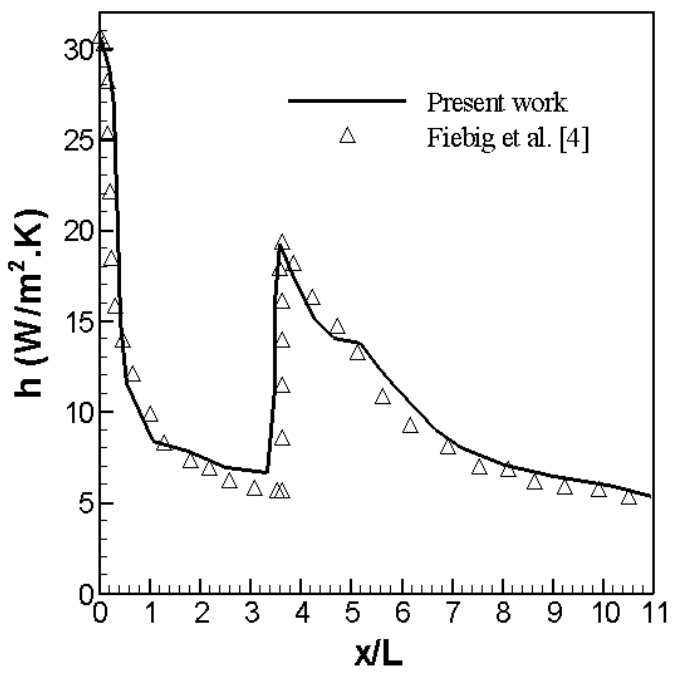

Figure 4. Local heat transfer coefficient behind a delta vortex generator for $\beta=40^{\circ}$ and $\mathrm{Re}=1815$

\section{RESULTS}

The numerical simulation based on equations $1-9$ is developed on ANSYS Fluent to simulate the effect of a triangular vortex generator on thermal and flow fields in a channel. Figure5 presents the streamlines around the wing at different attack angles showing the vortex generation behind the vortex generator. It is observed that by increasing the angle of rotation, larger vortices are created at the rear of the wing results in an increase in the pressure drop. 
(a)



(b)

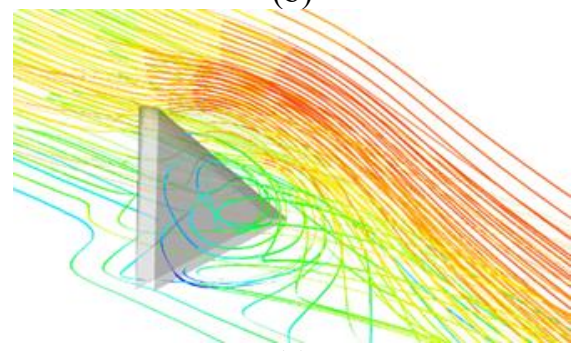

(c)

Figure 5. Streamlines for different rotational angles at $\mathrm{Re}=$ 456: (a) $\beta=30^{\circ}$, (b) $\beta=60^{\circ}$, and (c) $\beta=90^{\circ}$

Figures 6 and 7 shows isothermal contours at $\mathrm{Re}=456$ and $\mathrm{Re}=911$ for different angles of the vortex generator, respectively. The figures reveal that the thermal boundary layer around the wing is thinner for higher Reynolds numbers. As the Reynolds number increases, the low-temperature fluid penetrates at the greater part of the channel leads to an increase in heat transfer due to higher flow temperature gradient.

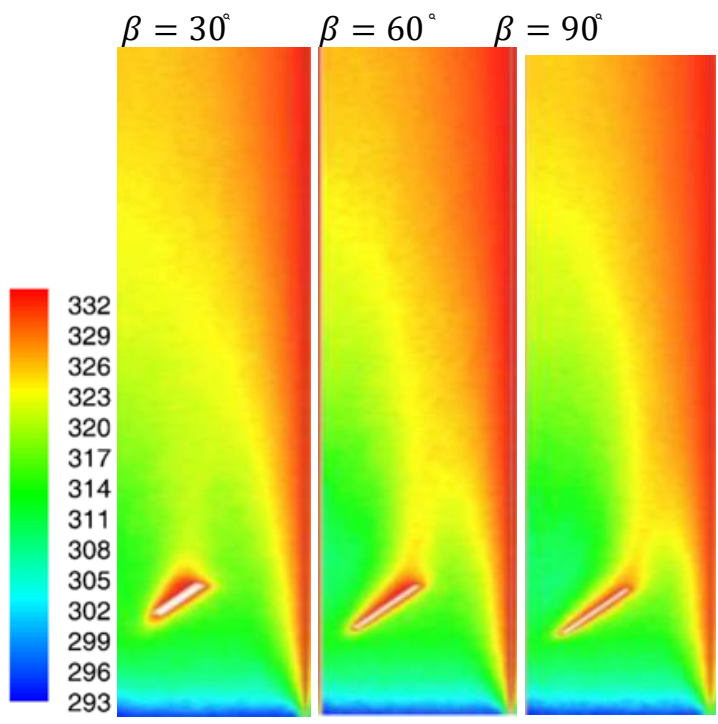

Figure 6. Isotherms for different vortex generator angles at $\mathrm{Re}=456$ for the cross section of $\mathrm{z}=\mathrm{H} / 8$

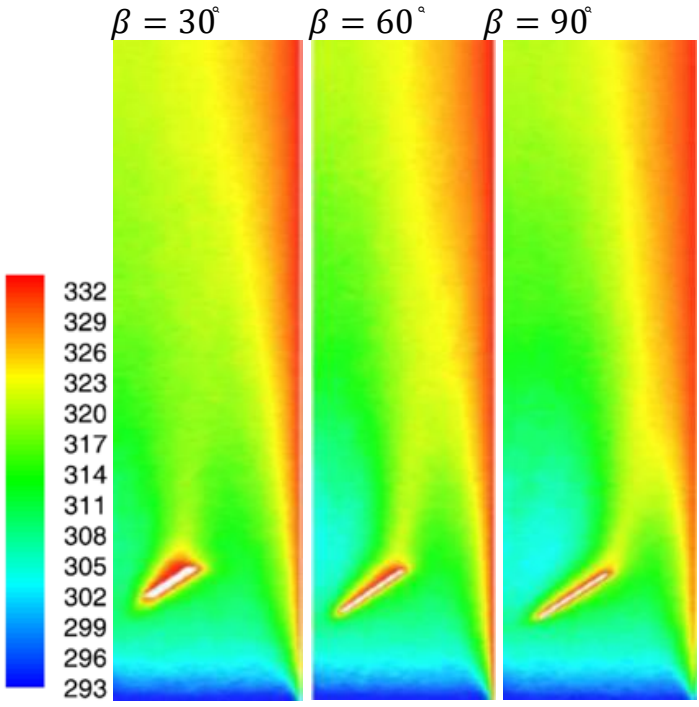

Figure 7. Isotherms for different vortex generator angles at $\mathrm{Re}=911$ for the cross section of $\mathrm{z}=\mathrm{H} / 8$

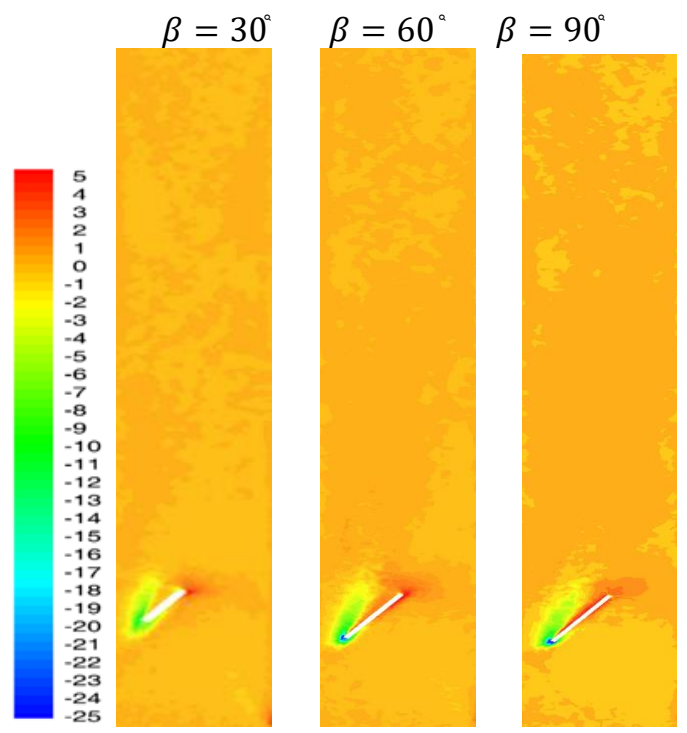

Figure 8. Vorticity contours for different vortex generator angles at $\mathrm{Re}=456$ for the cross section of $\mathrm{z}=\mathrm{H} / 2$

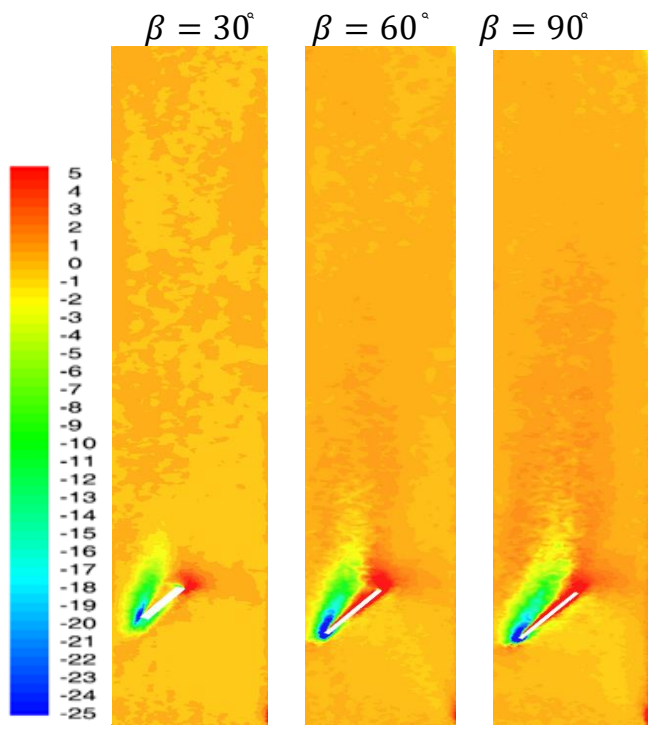

Figure 9. Vorticity contours for different vortex generator angles at $\operatorname{Re}=911$ for the cross section of $z=H / 2$ 
Vorticity contours are presented in Figs. 8 and 9 for different angles of the vortex generator. It can be concluded that at a constant elevation and constant Reynolds number, the longitudinal vortices extend over longer than the length of the channel by increasing the angle of rotation and their velocity increases. As the Reynolds number increases, the mass flow becomes higher. Higher rate of mass flow collide with the wing causes longer longitudinal vortices. This phenomenon is observed in the comparison of vorticity contours for a constant cross section for the two Reynolds numbers 456 and 911.

Isothermal contours are shown in Figures 10 and 11 for different cross sections: $\mathrm{y}=\mathrm{H} / 8,3 \mathrm{H} / 8$, and $\mathrm{H} / 2$. It is observed that the thickness of the thermal boundary layer on the walls of the channel decreases along with the channel. The fluid flow at a lower temperature, penetrates more in the longitudinal direction of the channel due to the effect of the vortex generator. The effect of increasing the Reynolds number on the reduction of the thermal boundary layer is obvious especially at the end of the channel. The input flow initially has a low temperature. Its temperature increases due to the friction caused by the collision of the fluid with the channel walls and the flow is gradually warmed up especially after collision with the vortex generator.

$$
\begin{aligned}
& \beta=30 \\
& \beta=60 \\
& \beta=90 \\
& \beta=30 \\
& \beta=60 \\
& \beta=90 \\
& \beta=30 \\
& \beta=60 \\
& \beta=90
\end{aligned}
$$



(a)



(b)

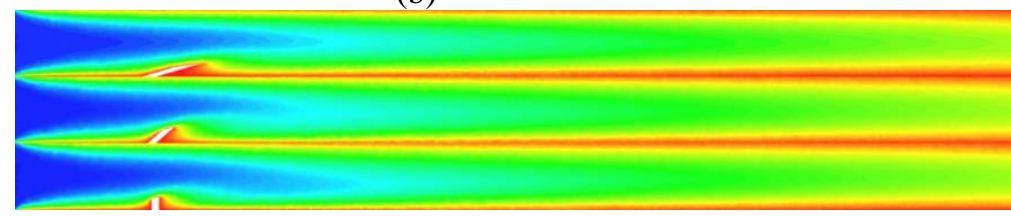

(c)

Figure 10. Isotherms for different vortex generator angles at $\mathrm{Re}=456$ for different cross sections in the $\mathrm{z}$-direction: (a) $\mathrm{y}=\mathrm{H} / 8$, (b) $y=3 H / 8,(c) y=H / 2$

$$
\begin{aligned}
& \beta=30 \\
& \beta=60 \\
& \beta=90 \\
& \beta=30 \\
& \beta=60 \\
& \beta=90 \\
& \beta=30 \\
& \beta=60 \\
& \beta=90
\end{aligned}
$$

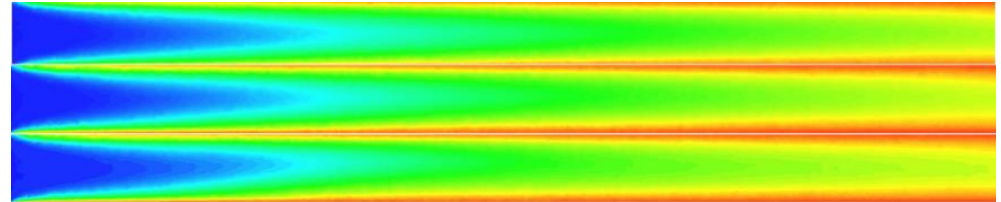

(a)



(b)



(c)

293296299302305308311314317320323326329332

Figure 11. Isotherms for different vortex generator angles at $\mathrm{Re}=911$ for different cross sections in the $\mathrm{z}$-direction: (a) $\mathrm{y}=\mathrm{H} / 8$, (b) $y=3 H / 8$, (c) $y=H / 2$ 
Figures 12 and 13 show the isothermal contours in three longitudinal sections. It is clearly seen that at a constant Reynolds number, the longitudinal vortices (which are seen in each longitudinal section in the form of a transverse vortex) are stronger with increasing rotational angles and occupy more area. It is also seen that the direction of rotation of the vortices in the positive direction of the longitudinal axis is counterclockwise. At a constant Reynolds number, the presence of the wing in the channel increases the mixing of hot and cold flows as the angle of rotation increases from 30 to 90 . In other words, the heat transfer increases with the rotational angle. Also, at a constant cross-section and a constant angle of the wing, the turbulence rate increases with increasing the Reynolds number leads to an increase in the heat transfer rate.

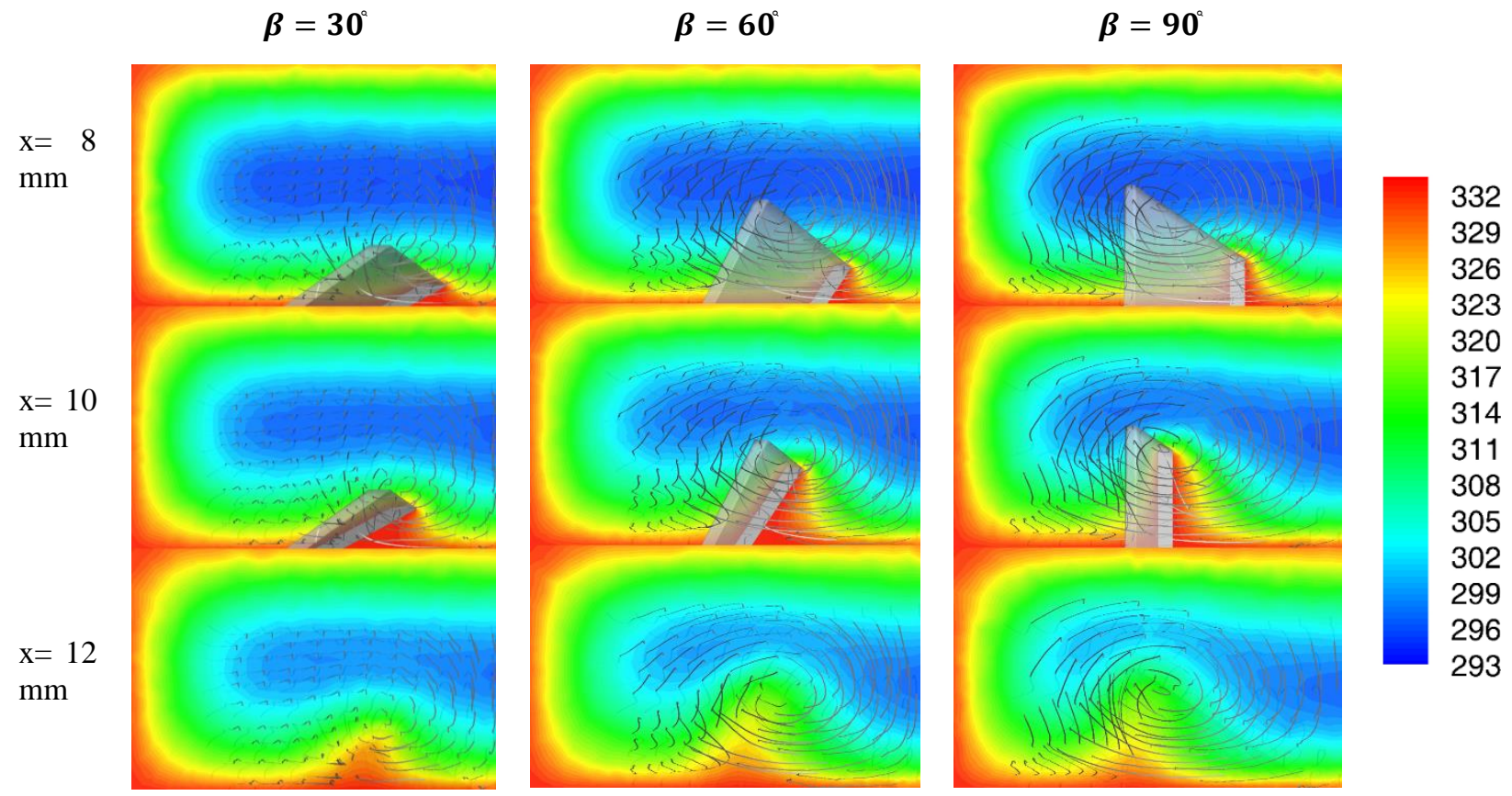

Figure 12. Isotherms for different vortex generator angles at $\mathrm{Re}=456$ for different cross sections in the $\mathrm{x}$-direction

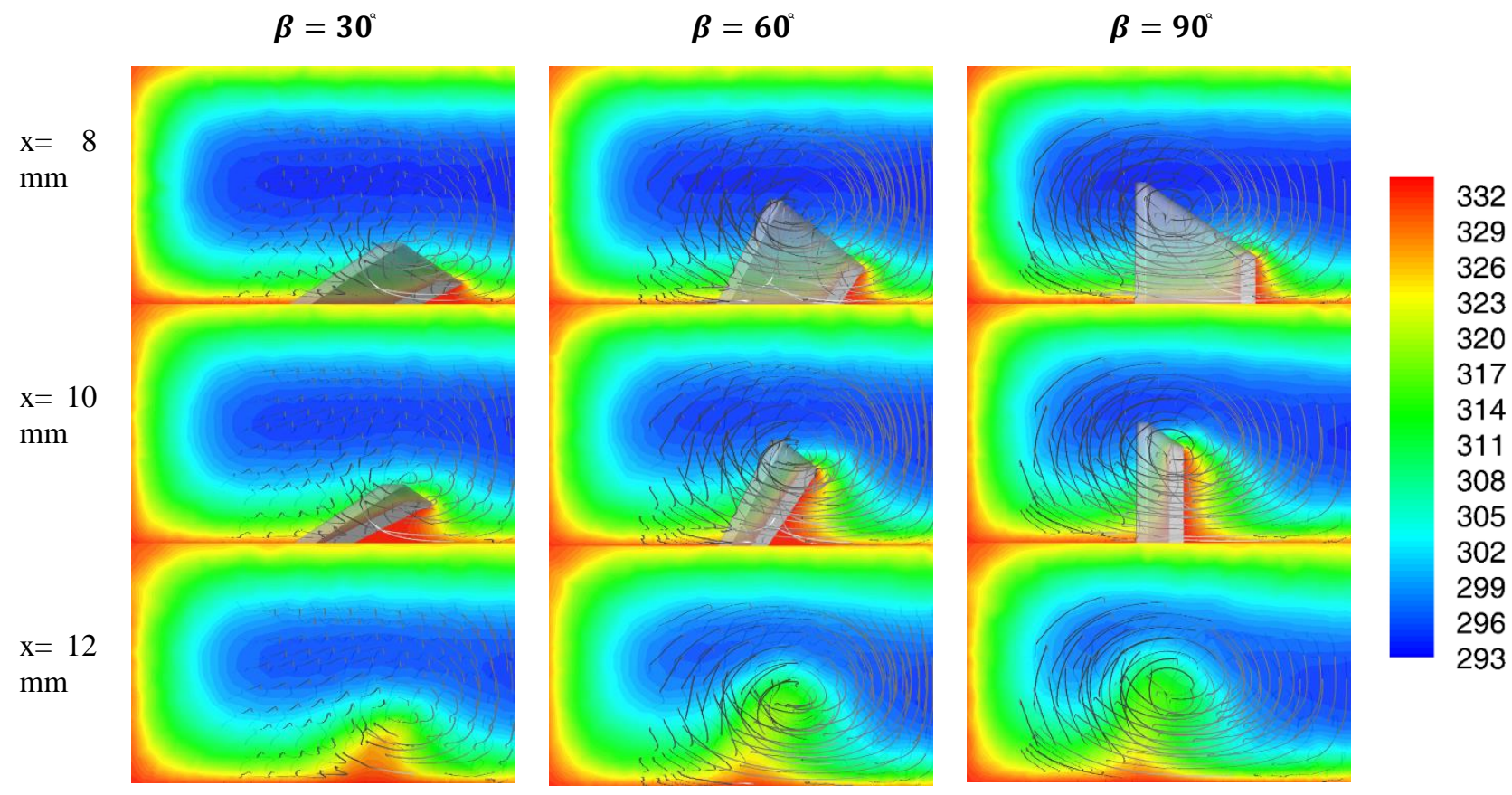

Figure 13. Isotherms for different vortex generator angles at $\mathrm{Re}=911$ for different cross sections in the $\mathrm{x}$-direction

In Table 2, the ratio of heat transfer in channel walls to the total heat transfer is given at the wing angles of $30^{\circ}, 60^{\circ}$ and $90^{\circ}$. In this table, $q_{b}$ represents the heat transfer from the bottom wall of the channel, $q_{s}$ the heat transfer from the side wall of the channel, $q_{t}$ the heat transfer from the up wall of the channel, and $q_{w}$ represents the heat transfer from the wing to the fluid. It can be seen that at $\beta=30^{\circ}$, the heat transfer of bottom wall, up wall and the wing decreases but the heat transfer of the side walls of the channel increases with the Reynolds number. At $\beta=60^{\circ}$ and $\beta=90^{\circ}$, the heat transfer 
from lower and side walls increases, however the heat transfer from the up wall and the wing decreases with the Reynolds number.

At $\mathrm{Re}=456$, it is observed that the heat transfer from the bottom wall and the wing increases with the angle. Also, the heat transfer from up and side walls decreases as the angle of vortex generator increases. At $R e=911$, it is concluded that the heat transfer from bottom wall and the wing increases and the heat transfer from up and side walls decreases by increasing the angle of rotation.

The simulations are performed for different Reynolds numbers. The variation of the Nusselt number as a function of
Reynolds number is plotted in Figure 14 for different angles. It can be seen that the Nusselt number increases linearly with the Reynolds number. It is also concluded that the enhancement of the Nusselt number increases with Reynolds number as the rotational angle increases. It should be noted that slight changes are observed in the Nusselt number from the angle of 60 to the angle of 90 . In other words, it can be assumed that the Nusselt number approximately remain constant for the range of 60 to 90 degrees. Therefore, the rotational angle does not affect the Nusselt number for this range of rotational angle.

Table 2. Dimensionless heat transfer from the channel surfaces and vortex generator for different angles and various Reynolds numbers

\begin{tabular}{|c|c|c|c|c|c|c|}
\hline & \multicolumn{2}{|c|}{$\beta=30$} & \multicolumn{2}{c|}{$\beta=60$} & \multicolumn{2}{c|}{$\beta=90$} \\
\hline$R e$ & 456 & 911 & 456 & 911 & 456 & 911 \\
\hline$q_{b} / q_{\text {total }}$ & 0.3950 & 0.3933 & 0.4024 & 0.4065 & 0.4139 & 0.4234 \\
\hline$q_{s} / q_{\text {total }}$ & 0.1651 & 0.1758 & 0.1626 & 0.1718 & 0.1586 & 0.1653 \\
\hline$q_{t} / q_{\text {total }}$ & 0.4156 & 0.4085 & 0.4064 & 0.3959 & 0.3953 & 0.3819 \\
\hline$q_{w} / q_{\text {total }}$ & 0.0244 & 0.0224 & 0.0286 & 0.0258 & 0.0323 & 0.0293 \\
\hline
\end{tabular}

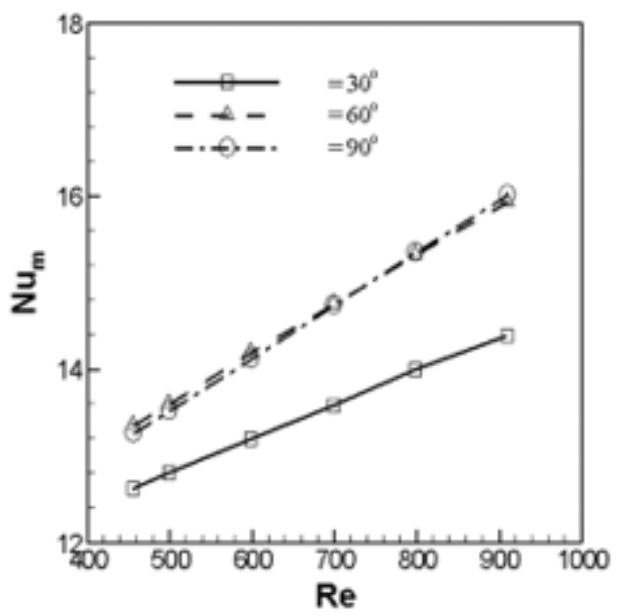

Figure 14. Nusselt number versus Reynolds number for different rotational angle

The pressure drop is one of the most important parameter that should be considered for the present problem. As shown in Figure 15, the pressure drop increases at rotational angles of 30 and 90. High-pressure areas are formed in front of the wing with increasing the Reynolds number. At a constant Reynolds number and the specified height, the pressure drop increases with the rotation angle. The pressure on the front surface of the wing increases as the rotational angle increases. By increasing the angle of rotation, the magnitude of the maximum pressure difference within the channel increases. In other words, the more areas of the channel have the maximum pressure difference. It can also be seen that the pressure drop significantly increases as the rotation angle increases at a constant Reynolds number. It is worth noting that for the rotational angle of 60 , the pressure drop remains constant as the Reynolds number increases. Therefore, due to the variation of Nusselt number that is previously described, and the changes in the pressure drop, it is concluded that the angle of 60 results in higher heat transfer than the angle of 90 . This is due to that the angle of 60 provides the same Nusselt number in comparison with the angle of 90 , but it experiences less pressure drop. With increasing Reynolds number and consequently increasing Nusselt number, the pressure drop remains constant.



Figure 15. Pressure drop versus Reynolds number for different rotational angle

\section{CONCLUSIONS}

The Nusselt number increases linearly with the Reynolds number for all angles of rotation. As the angle of rotation increases, the rate of variation of the Nusselt number increases with Reynolds number. Slight changes are observed in the Nusselt number as the rotational angle increases from 60 to 90 . In other words, it can be assumed that the Nusselt number remains constant for different Reynolds numbers for the range of 60 to 90 rotational angle. So, the change in the angle of rotation does not affect on Nusselt number. It was observed that the pressure drop increases with the rotational angle. Also, at a constant Reynolds number, the pressure drop significantly increases with increasing the rotational angle. But, for the rotation angle of 60 , the pressure drop remains constant as the Reynolds number increases. Therefore, due to the variation of Nusselt number that is previously described, and the changes in the pressure drop, it is concluded that the angle of 60 results 
in higher heat transfer than the angle of 90 . By increasing the angle of rotation, larger vortices are generated behind the wing results in a higher pressure drop. It was observed that with the increase of the Reynolds number, the thermal boundary layer around the vortex generator becomes thinner. The fluid with a lower temperature penetrates more of the channel, indicating an increase in the transfer of heat transfer. At all angles of rotation, the boundary layer of the velocity around the wing is thinner and the flow penetrates more rapidly in the channel at higher Reynolds numbers. As the Reynolds number increases, the high-pressure areas are formed in front of the wing. Also, at a constant Reynolds number and the specified height, the pressure drop increases with the rotation angle. The pressure on the front surface of the wing increases as the rotational angle increases. At a constant Reynolds number, the presence of the wing in the channel increases the mixing of hot and cold flows as the angle of rotation increases. In addition, the references [26-30] are introduced for different geometries and flow characteristics.

\section{REFERENCES}

[1] Schubauer GB, Spangenberg WG. (1960). Forced mixing in boundary layers. Journal of Fluid Mechanics 8(1): 1032. http://dx.doi.org/10.1017/S0022112060000372

[2] Johnson TR, Joubert PN. (1969). The influence of vortex generators on the drag and heat transfer from a circular cylinder normal to an airstream. Journal of Heat Transfer 91(1): 91-99. http://dx.doi.org/10.1115/1.3580126

[3] Dupont F, Gabillet C, Bot P. (2003). Experimental study of the flow in a compact heat exchanger channel with embossed-type vortex generators. Journal of Fluids Engineering $\quad 125(4)$ : 701-709. http://dx.doi.org/10.1115/1.1595675

[4] Fiebig M, Kallweit P, Mitra N, Tiggelbeck S. (1991). Heat transfer enhancement and drag by longitudinal vortex generators in channel flow. Experimental Thermal and Fluid Science 4(1): 103-114 http://dx.doi.org/10.1016/0894-1777(91)90024-L

[5] Russell CM. (1986). The development of a high performance heat transfer surface. In Heat Transfer Conference, pp. 843-855.

[6] Lin CN, Jang JY. (2002). Conjugate heat transfer and fluid flow analysis in fin-tube heat exchangers with wave-type vortex generators. Journal of Enhanced Heat Transfer 9(3-4): 123-136 http://dx.doi.org/10.1080/10655130215737

[7] Leu JS, Wu YH, Jang JY. (2004). Heat transfer and fluid flow analysis in plate-fin and tube heat exchangers with a pair of block shape vortex generators. International Journal of Heat and Mass Transfer 47(19): 4327-4338. http://dx.doi.org/10.1016/j.ijheatmasstransfer.2004.04.0 31

[8] Lei YG, He YL, Tian LT, Chu P, Tao WQ. (2010). Hydrodynamics and heat transfer characteristics of a novel heat exchanger with delta-winglet vortex generators. Chemical Engineering Science 65(5): 15511562. http://dx.doi.org/10.1016/j.ces.2009.10.017

[9] Joardar A, Jacobi AM. (2007). A numerical study of flow and heat transfer enhancement using an array of deltawinglet vortex generators in a fin-and-tube heat exchanger. Journal of Heat Transfer 129(9): 1156-1167. http://dx.doi.org/10.1115/1.2740308
[10] Joardar A, Jacobi AM. (2008). Heat transfer enhancement by winglet-type vortex generator arrays in compact plain-fin-and-tube heat exchangers. International Journal of refrigeration 31(1): 87-97. http://dx.doi.org/10.1016/j.ijrefrig.2007.04.011

[11] Didarul IM, Kenyu O, Minoru Y, Izuru S. (2007). Study on heat transfer and fluid flow characteristics with short rectangular plate fin of different pattern. Experimental Thermal and Fluid Science 31(4): 367-379. http://dx.doi.org/10.1016/j.expthermflusci.2006.05.009

[12] Gorji M, Mirgolbabaei H, Barari A, Domairry G, Nadim N. (2011). Numerical analysis on longitudinal location optimization of vortex generator in compact heat exchangers. International Journal for Numerical Methods in Fluids 66(6): 705-713. http://dx.doi.org/10.1002/fld.2278

[13] Wang Q, Chen Q, Wang L, Zeng M, Huang Y, Xiao Z. (2007). Experimental study of heat transfer enhancement in narrow rectangular channel with longitudinal vortex generators. Nuclear Engineering and Design 237(7): 686693. http://dx.doi.org/10.1016/j.nucengdes.2006.09.003

[14] Wu JM, Tao WQ. (2008). Numerical study on laminar convection heat transfer in a channel with longitudinal vortex generator. Part B: Parametric study of major influence factors. International Journal of Heat and Mass Transfer 51(13): 3683-3692.

[15] Wu JM, Tao WQ. (2008). Numerical study on laminar convection heat transfer in a rectangular channel with longitudinal vortex generator. Part A: Verification of field synergy principle. International Journal of Heat and Mass Transfer 51(5): 1179-1191. http://dx.doi.org/10.1016/j.ijheatmasstransfer.2007.03.0 32

[16] Tiggelbeck ST, Mitra NK, Fiebig M. (1994). Comparison of wing-type vortex generators for heat transfer enhancement in channel flows. Journal of Heat Transfer 116(4): 880-885. http://dx.doi.org/10.1115/1.2911462

[17] Gentry MC, Jacobi AM. (2002). Heat transfer enhancement by delta-wing-generated tip vortices in flatplate and developing channel flows. Urbana 51: 61801. http://dx.doi.org/10.1115/1.1513578

[18] Yang JS, Seo JK, Lee KB. (2001). A numerical analysis on flow field and heat transfer by interaction between a pair of vortices in rectangular channel flow. Current Applied Physics 1(4): 393-405. http://dx.doi.org/10.1016/S1567-1739(01)00042-6

[19] Liou TM, Chen CC, Tsai TW. (1999, June). Heat transfer and fluid flow in a square duct with 12 different shaped vortex generators. In ASME 1999 International Gas Turbine and Aeroengine Congress and Exhibition (pp. V003T01A073-V003T01A073). American Society of Mechanical Engineers.

[20] Zhu JX, Fiebig M, Mitra NK. (1995). Numerical investigation of turbulent flows and heat transfer in a ribroughened channel with longitudinal vortex generators. International Journal of Heat and Mass Transfer 38(3): 495-501. 9310(94)00177-W

[21] Fiebig M. (1995). Embedded vortices in internal flow: Heat transfer and pressure loss enhancement. International Journal of Heat and Fluid Flow 16(5): 376388. http://dx.doi.org/10.1016/0142-727X(95)00043-P

[22] Hiravennavar SR, Tulapurkara EG, Biswas G. (2007). A note on the flow and heat transfer enhancement in a 
channel with built-in winglet pair. International Journal of Heat and Fluid Flow 28(2): 299-305. http://dx.doi.org/10.1016/j.ijheatfluidflow.2006.03.030

[23] Ferrouillat S, Tochon P, Garnier C, Peerhossaini H. (2006). Intensification of heat-transfer and mixing in multifunctional heat exchangers by artificially generated streamwise vorticity. Applied Thermal Engineering 26(16): 1820-1829.

[24] Abdollahi A, Shams M. (2015). Optimization of shape and angle of attack of winglet vortex generator in a rectangular channel for heat transfer enhancement. Applied Thermal Engineering 81: 376-387.

[25] Khanjian A, Habchi C, Russeil S, Bougeard D, Lemenand T. (2017). Effect of rectangular winglet pair roll angle on the heat transfer enhancement in laminar channel flow. International Journal of Thermal Sciences 114: $1-14$. http://dx.doi.org/10.1016/j.ijthermalsci.2016.12.010

[26] Jahanbakhshi A, Ahmadi Nadooshan A, Bayareh M. (2018). Magnetic field effects on natural convection flow of a non-Newtonian fluid in an L-shaped enclosure. Journal of Thermal Analysis and Calorimetry 133: 14071416. http://dx.doi.org/10.1007/s10973-018-7219-6

[27] Sepyani M, Shateri A, Bayareh M. (2018). Investigating the mixed convection heat transfer of a nanofluid in a square chamber with a rotating blade. Journal of Thermal Analysis and Calorimetry 133: 1-15. http://dx.doi.org/10.1007/s10973-018-7098-x

[28] Bayareh M, Kianfar A, Kasaeipour A. (2018). Mixed convection heat transfer of water-alumina nanofluid in an inclined and baffled c-shaped enclosure. Journal of Heat and Mass Transfer Research. http://dx.doi.org/10.22075/jhmtr.2018.13390.1196

[29] Nourbakhsh A, Bayareh M. (2018). Numerical study of natural convection heat transfer of $\mathrm{Al}_{2} \mathrm{O}_{3} /$ Water nanofluid in a -shaped microchannel. Energy Equipment and Systems 6: 143-154. http://dx.doi.org/10.22059/ees.2018.31533

[30] Piombini H, Boscher C, Barre AL, Avice J. (2017). Identification de faïençage de couche mince sol-gel.
Instrumentation, Mesure, Metrologie 16: 1-4. https://doi.org/10.3166/i2m.16.1-4.143-164

\section{NOMENCLATURE}

\begin{tabular}{ll}
$A$ & area of wall \\
$A_{\text {winglet }}$ & area of wings \\
CP & specific heat at constant pressure \\
$D_{h}$ & hydraulic diameter \\
$E$ & thickness of the wings \\
$H$ & height of the channel \\
$h$ & Convective heat transfer coefficient \\
$K$ & height of the wings \\
$k_{f}$ & thermal conductivity of the fluid \\
$L$ & length of the channel \\
$N u$ & Nusselt number \\
$p_{\text {in }}$ & inlet pressure \\
$p_{\text {out }}$ & output pressure \\
Pr & Prandtl number \\
$q$ & Total heat transfer \\
$q_{b}$ & heat transfer from the bottom wall of the channel \\
$q_{s}$ & heat transfer from the side wall of the channel \\
$q_{t}$ & heat transfer from the up wall of the channel \\
$q_{w}$ & heat transfer from the wing to the fluid \\
$\operatorname{Re}$ & Reynolds number \\
$S$ & length of the wings \\
$T_{i n}$ & inlet temperature \\
$T_{\text {out }}$ & output temperature \\
$T_{w}$ & wall temperature and wings temperature \\
$\vec{u}$ & velocity vector \\
$W$ & width of the channel \\
$\alpha$ & angle of attack \\
$\beta$ & rotational angle \\
$\mu$ & density \\
& viscosity \\
\hline &
\end{tabular}

